\title{
Determination of Gas Diffusivity and Skin Resistance for Three Cultivars of Japanese Pear Using their Actual 3D Geometry
}

\author{
Maryam Ebrahim ReZagah ${ }^{1}$, Sayaka IshidA ${ }^{1}$, Fumihiko TAnAKA ${ }^{2}$, Toshitaka UChinO ${ }^{2}$, \\ Daisuke HAMANAKA ${ }^{2}$ and Yoshio HIKIDA ${ }^{3}$ \\ 'Graduate School of Bioresources and Bioenvironmental Sciences, Kyushu University, \\ 6-10-1 Hakozaki, Higashi-ku, Fukuoka 812-8581, Japan \\ ${ }^{2}$ Faculty of Agriculture, Kyushu University, 6-10-1 Hakozaki, Higashi-ku, Fukuoka 812-8581, Japan \\ ${ }^{3}$ Faculty of Agriculture, Ehime University, 3-5-7 Tarumi, Matsuyama, Ehime 970-8566, Japan
}

(Received October 15, 2013; Accepted November 19, 2013)

\begin{abstract}
This research was conducted to study gas transfer in three cultivars of Japanese pear based on their actual geometry obtained from a 3D Laser Scanner. Gas diffusivity and skin resistance to gas diffusion found to be dependent on the cultivar. Gas diffusivity for ethane was found to be $8.10 \pm 1.2,3.67 \pm 0.11$ and $5.97 \pm 0.42\left(\times 10^{-8} \mathrm{~m}^{2} \mathrm{~s}^{-1}\right)$ for Kosui, Niitaka and Oushuu, respectively. Niitaka was found to have the highest skin resistance due to a noticeably lower number of lenticels on the skin. As expected gas diffusivity increased with increasing of temperature while skin resistance decreased. It was found that the diffusivity of $\mathrm{CO}_{2}$ is much lower than $\mathrm{O}_{2}$. The model was validated by conducting experiments to measure the internal concentration at different points of the fruit and comparing them with model results. The model was shown to be successful in predicting the internal gas concentrations.
\end{abstract}

Keywords : COMSOL Multiphysics 4.2a, gas transfer modeling, Kosui, NextEngine 3D Scanner, Niitaka, Oushuu

\section{INTRODUCTION}

The storage life of fruits and their year-round availability to consumers critically depends on their gas exchange properties. Unfavorable composition of the internal atmosphere can cause internal disorders in fruits during storage but the internal atmosphere of fruit is difficult to deduce from the external atmosphere due to gas transport, consumption and production (Schotsmans et al., 2002; Ho et al., 2006). Thus it is difficult to measure the internal gas concentrations from the surrounding atmosphere. The knowledge of gas transport properties is essential for calculating the internal concentration of $\mathrm{O}_{2}$ and $\mathrm{CO}_{2}$ in the fruit when the storage gas concentrations are known. The skin represents the major barrier to gas exchange and its resistance as well as fruit flesh gas diffusivity can be estimated by measuring the rate at which a tracer gas, which has been absorbed previously, is released from the fruit (Solomos, 1987; Pham et al., 2009). The change in concentration can be described using Fick's first law of diffusion (Banks, 1985; Schotsmans et al., 2002; Pham et al., 2009). However, there is limited information on characteristics of the fruits of Japanese pear especially its gas transport properties; hence it was necessary to conduct the present study.

On the other hand, geometrical characterization of an object is required to make a model for analytical or numerical solutions. However, most agricultural products do not appear to be uniform with respect to their 3D irregular shapes, yet in modeling studies, assuming homogenous, isotropic products with regular shapes has been a traditional approach (Borsa et al., 2002; Uyar and Erdoğdu, 2009). Geometry of an object can be simulated by means of computer aided design (CAD) and CFD programs. However, there is still an important issue regarding how to obtain the exact shape of products with all their features and irregularities. Using the exact shape of an object is a tedious and difficult task especially for irregular shaped food products and there are not many studies published based on exact geometry of these products (Goñi et al., 2007; Uyar and Erdoğdu, 2009; Celik et al., 2011; Fabbri et al., 2011; Kelkar et al., 2011).

Therefore, this study focuses on modeling of gas transfer based on efflux method using ethane and estimating gas diffusivity and skin resistance of three cultivars of Japanese pear (Pyrus pyrifolia) for respiratory gases during storage at $5^{\circ} \mathrm{C}$ using their actual $3 \mathrm{D}$ geometry to be used later in designing and optimizing of cold storage and transportation systems for this fruit.

\section{MATERIALS AND METHODS}

\section{Materials}

In present study, three cultivars of Japanese pear namely, Kosui, Niitaka and Oushuu, were used. Kosui, harvested in late July to mid-August, is a round medium size fruit with a green skin color, resistant to Alternaria black spot, moderately resistant to pear scab, with no oc-

Corresponding author: Fumihiko Tanaka, fax: + 81-92-642-2935, e-mail : fumit@bpes.kyushu-u.ac.jp 
currence of browning when sliced. Niitaka, harvested during mid-October to mid-November, is a large round fruit with heavily russet skin color. Oushuu, harvested around late October to November, is a late ripening cultivar with large fruit size that arose from crossbreeding of cultivars with reduced occurrence of water core. Samples of each cultivar were obtained from Fukuoka Agricultural Research Center, at the same time, from the same lot of fruits and were kept in a $2{ }^{\circ} \mathrm{C}$ refrigerator to keep their respiration to the least possible level until the experiments were done.

The $3 D$ geometry, volume and density

The 3D image of each pear was obtained using NextEngine 3D Laser Scanner (NextEngine Inc.) with standard speed (SD) settings (about $6.45 \times 10^{8}$ points $\mathrm{m}^{-2}$ ) and macro range settings with $0.0001 \mathrm{~m}$ accuracy. Other configurations were set as one family with $360^{\circ}$ positioning and 7 divisions followed by two scan families with single positioning in order to scan the top and bottom of the fruit (E. Rezagah et al., 2013).

The scanner functions with a scanning software called NextEngine ScanStudio HD 1.3.2, which makes it possible to combine the separated surface scans into one surface (align function), merge volume and simplify the surface meshing. Volume of the geometry can be measured with ScanStudio CAD TOOLS in the same software.

The accuracy of the volume measurements was examined by measuring the diameter of a sphere-shaped object with 5 replications by a digital caliper with accuracy of 0.0002 m (Digimatic caliper, Mitutoyo Co., Japan), calculating the sphere's volume knowing its radius and comparing it with the volume obtained from the 3D laser scanner (E. Rezagah et al., 2013).

The output of each geometry file was saved in ".stl" format to later import in COMSOL Multiphysics 4.2a software for further modeling (Fig. 1). Mesh construction was created in COMSOL Multiphysics 4.2a code and tetrahedral solid element type was used for the mesh construction. About 13,770, 18,000 and 13,700 tetrahedral elements were obtained for mesh construction of the model in case of Kosui, Niitaka and Oushuu, respectively. The model was written using the "Transport of Diluted Species" node of the "Chemical Species Transport" in COMSOL.

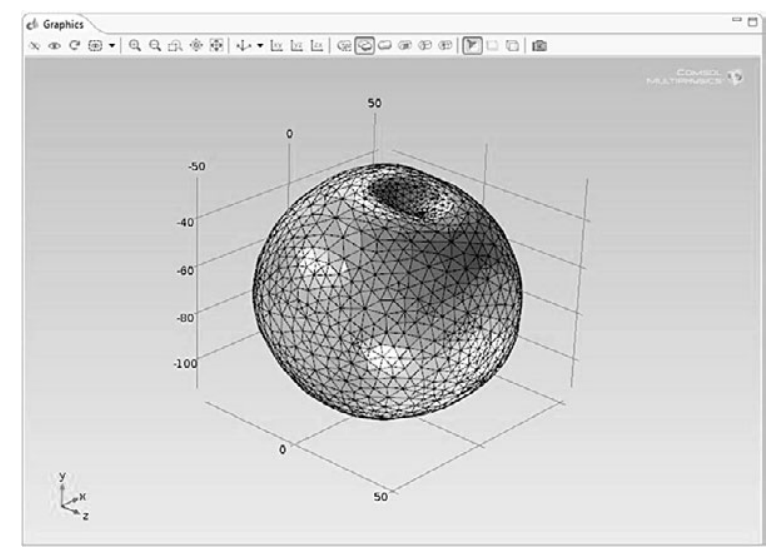

Fig. 1 Imported 3-dimensional model of Japanese pear (Niitaka).
Knowing the volume of the pear and measuring the weight of the pear permits us to calculate the bulk density of the fruit using Eq. (1).

$$
\rho_{\mathrm{b}}=\frac{\mathrm{m}}{\mathrm{V}}
$$

where $\rho_{\mathrm{b}}$ is the bulk density of the whole fruit $\left(\mathrm{g} \mathrm{cm}^{-3}\right), \mathrm{m}$ is the weight of the pear $(\mathrm{g})$ and $\mathrm{V}$ is the volume of the pear $\left(\mathrm{cm}^{3}\right)$.

Solid-liquid density of the fruit was measured from measuring the weight of $100 \mathrm{~cm}^{3}$ of a sample previously pulped, homogenized and de-aerated in order to eliminate pores and air (Nieto et al., 2004). The porosity of pear was then calculated from Eq. (2):

$$
\varepsilon=\frac{\rho_{\mathrm{s}}-\rho_{\mathrm{b}}}{\rho_{\mathrm{s}}}
$$

where $\varepsilon$ is the porosity (dimensionless), $\rho_{\mathrm{b}}$ is the bulk density of the whole fruit $\left(\mathrm{g} \mathrm{cm}^{-3}\right)$ and $\rho_{\mathrm{s}}$ is solid-liquid density of the fruit flesh $\left(\mathrm{g} \mathrm{cm}^{-3}\right)$.

Efflux experiments

Gas diffusion was studied in macro-scale by putting a fruit that was previously soaked in a tracer gas, in a sealed jar and measuring the rate at which the tracer gas diffuses out of the fruit. In the present study, ethane was used as the tracer gas and injected at a concentration of $1,000 \mathrm{ppm}$ to an 18 liter permeation jar, where the pear samples with initial internal ethane concentration of zero were soaked in ethane at $5^{\circ} \mathrm{C}$ for 3 days. This long period was chosen to ensure the equilibrium conditions will reach and ethane will be distributed uniformly throughout the fruit. The fruit was then quickly transferred to a new 9 liter jar filled with air without any ethane. To ensure that the second jar was not contaminated by ethane from the first jar, it was opened in another room and the pear samples were quickly wiped with a tissue and taken to the cold room with $5^{\circ} \mathrm{C}$. Changes of ethane, $\mathrm{CO}_{2}$ and $\mathrm{O}_{2}$ concentrations were monitored using gas chromatography (GL Science GC390, Japan) with a WG-100 column, FID-TCD detector and helium as the carrier gas with flow rate of $30 \mathrm{ml} \mathrm{min}^{-1}$. Column temperature was set at $60^{\circ} \mathrm{C}$, injection temperature at $100^{\circ} \mathrm{C}$, FID temperature at $150^{\circ} \mathrm{C}$ and $\mathrm{TCD}$ temperature at $80^{\circ} \mathrm{C}$. Gas concentration measurements were done for $12 \mathrm{~h}$, followed by 3 more sampling the next morning to obtain the equilibrium concentrations. All experiments were done with three replications.

Determination of gas transfer properties based on ethane

Ethane is inert, has low solubility in water and is not consumed or produced by the fruit. According to Pham et al. (2009), Fick's law can be written for ethane in the fruit in the following form:

$$
\frac{\partial \mathrm{c}}{\partial \mathrm{t}}=\nabla \cdot(\mathrm{D} \nabla \mathrm{c})
$$

where $\mathrm{c}$ is concentration of ethane in the pear $\left(\mathrm{mol} \mathrm{m}^{-3}\right)$ and $\mathrm{D}$ is effective diffusivity $\left(\mathrm{m}^{2} \mathrm{~s}^{-1}\right)$. The boundary condition is: 


$$
\mathbf{n} \cdot(\mathrm{D} \nabla \mathrm{c})=\mathrm{Kh}_{\mathrm{c}}\left(\frac{\mathrm{c}_{\mathrm{ext}}}{\mathrm{K}}-\mathrm{c}_{\text {surf }}\right)
$$

where $\mathbf{n}$ is the unit normal vector, $\mathrm{K}$ is the distribution coefficient $\left(\left(\mathrm{mol} \mathrm{m}{ }^{-3}\right.\right.$ in air $) /\left(\mathrm{mol} \mathrm{m}{ }^{-3}\right.$ in fruit $\left.)\right), h_{c}$ is the mass transfer coefficient $\left(\mathrm{m} \mathrm{s}^{-1}\right), \mathrm{c}_{\mathrm{ext}}$ is the concentration of ethane in the $\mathrm{jar}\left(\mathrm{mol} \mathrm{m}{ }^{-3}\right)$ and $\mathrm{c}_{\text {surf }}$ is the ethane concentration at the fruit surface $\left(\mathrm{mol} \mathrm{m}^{-3}\right)$. The inverse of mass transfer coefficient $\left(h_{c}\right)$ is the surface resistance to mass transfer, $r_{\text {skin }}$ $\left(\mathrm{s} \mathrm{m}^{-1}\right.$ ) (Pham et al., 2009):

$$
\mathrm{h}_{\mathrm{c}}=\frac{1}{\mathrm{r}_{\text {skin }}}
$$

The concentration $\mathrm{c}_{\mathrm{ext}}$ in the efflux jar can be obtained from the material balance and rearranged to the following form:

$$
\mathrm{c}_{\mathrm{ext}}=\frac{\mathrm{V}}{\mathrm{V}_{\mathrm{ext}}}\left(\mathrm{c}_{\mathrm{avg}, \mathrm{o}}-\mathrm{c}_{\mathrm{avg}}\right)
$$

where $\mathrm{V}$ is the volume of the pear $\left(\mathrm{m}^{3}\right), \mathrm{V}_{\text {ext }}$ is the volume of the jar minus that of the fruit $\left(\mathrm{m}^{3}\right), \mathrm{c}_{\text {avg }}$ is the average concentration of ethane in the whole fruit $\left(\mathrm{mol} \mathrm{m}^{-3}\right)$ and $\mathrm{c}_{\text {avg,o }}$ is the average concentration at the beginning of efflux period $\left(\mathrm{mol} \mathrm{m}^{-3}\right)$.

For a pear that was initially equilibrated with a mixture of ethane-air at ethane concentration of $\mathrm{c}_{\mathrm{ext}, 0}$ in permeation jar, the internal concentration of ethane will be uniformly distributed Eq. (7).

$$
\mathrm{c}_{0}=\mathrm{c}_{\text {avg }, 0}=\frac{\mathrm{c}_{\text {ext,0}}}{\mathrm{K}}
$$

At an infinite time the whole fruit reaches equilibrium with the air in the jar so $c_{\text {ext,eq }}=\mathrm{Kc}_{\text {avg }}$ and

$$
c_{\text {ext,eq }}=\frac{\mathrm{V}}{\mathrm{V}_{\text {ext }}}\left(\mathrm{c}_{\text {avg }, 0}-\frac{1}{\mathrm{~K}} \mathrm{c}_{\text {ext,eq }}\right)
$$

Substituting $c_{\text {avg.0 }}$ from Eq. (7) gives Eq. (9) from which we can calculate the distribution coefficient.

$$
\begin{aligned}
& c_{\text {exteq }}=\frac{\mathrm{V}}{\mathrm{KV}_{\text {ext }}}\left(c_{\text {ext }, 0}-c_{\text {ext,eq }}\right) \\
& \mathrm{K}=\frac{\mathrm{V}}{\mathrm{V}_{\text {ext }}}\left(\frac{\mathrm{c}_{\text {ext,0}}}{\mathrm{c}_{\text {ext,eq }}}-1\right)
\end{aligned}
$$

Equations (3), (6), (9), and (10) were used in writing the gas transfer model in "Transport of Diluted Species" node of COMSOL Multiphysics 4.2a based on finite element method to obtain the estimated values for $\mathrm{D}, \mathrm{h}_{\mathrm{c}}$ and skin resistance for Kosui, Niitaka and Oushuu at $5^{\circ} \mathrm{C}$. On the other hand, knowing the distribution coefficient, Henry's law constant $\left(\left(\mathrm{mol} \mathrm{m}^{-3}\right.\right.$ in dense phase $) /\left(\mathrm{mol} \mathrm{m}^{-3}\right.$ in gas phase)) can be determined from Eq. (11):

$$
\mathrm{K}_{\mathrm{H}}=\frac{\frac{1}{\mathrm{~K}}-\varepsilon}{1-\varepsilon}
$$

Determination of gas transfer properties for $\mathrm{O}_{2}$ and $\mathrm{CO}_{2}$

In order to generalize the results of ethane diffusivity and predict the diffusivity of other gases tortuosity factor $(\tau)$ was calculated based on the co-diffusion model presented in Eq. (12) (Ho et al., 2006; Pham et al., 2008; Pham et al., 2009):

$$
\mathrm{D}=\mathrm{K}\left[\frac{\varepsilon}{\tau} \mathrm{D}_{\text {air }}+(1-\varepsilon) \mathrm{k}_{\mathrm{H}} \mathrm{D}_{\text {cells }}\right]
$$

where $D_{\text {air }}$ is diffusivity of gas in free air $\left(\mathrm{m}^{2} \mathrm{~s}^{-1}\right), \mathrm{D}_{\text {cells }}$ is diffusivity of gas in cells $\left(\mathrm{m}^{2} \mathrm{~s}^{-1}\right)$ and $\tau$ is a reduction factor that accounts for the tortuosity of the diffusing paths, variations in their cross-section areas and connectivity (dead pores). Tortuosity factor can be calculated by re-arranging Eq. (12) into the following form (Pham et al., 2009):

$$
\tau=\frac{\varepsilon D_{\text {air }}}{\frac{D}{K}-(1-\varepsilon) k_{H} D_{\text {cells }}}
$$

Porosity and tortuosity factor are the same for all gases since they are determined by geometry, while $\mathrm{D}_{\text {air }}$, $\mathrm{D}_{\text {cell }}$ and $\mathrm{k}_{\mathrm{H}}$ for different gases can be found from literature (Pham et al., 2009).

Calculation of skin resistance is more problematic than diffusivity. The co-diffusion model, Eq. (12), can be used together with the assumption that skin resistance is inversely proportional to the diffusivity in the denser layer of tissue at the surface. The problem is both $\varepsilon_{\text {skin }}$ and $\tau_{\text {skin }}$ are not known and since $\varepsilon_{\text {skin }}$ is much smaller in the skin region than the rest of the fruit, the second term, $\left[\left(1-\varepsilon_{\text {skin }}\right) \mathrm{k}_{\mathrm{H}} \mathrm{D}_{\text {cells }}\right]$, may not be negligible. If this term is neglected anyway, then

$$
\mathrm{r}_{\text {skin }} \propto \frac{\tau_{\text {skin }}}{\varepsilon_{\text {skin }} D_{\text {air }}}
$$

Since $\varepsilon_{\text {skin }}$ and $\tau_{\text {skin }}$ are common to all gases, the value of $\varepsilon_{\text {skin }} / \tau_{\text {skin }}$ can be calculated from the measurements of ethane. This means the skin resistance is inversely proportional to the diffusivity of the gas in air (Pham et al., 2009).

Model validation

For the purpose of validating the model and the estimated values of gas transfer coefficient as well as skin resistance, the exact concentration of ethane at different positions of Japanese pear, previously immersed in ethane, was measured according to the method explained by Kawano and Shimokawa (1994) and the values were compared with the model estimations. The cubic samples with volume of $1 \mathrm{~cm}^{3}$ were cut from the pear the way it is shown in Fig. 2.

The apparatus for extracting and determining ethane from Japanese pear tissue consists of a $100 \mathrm{ml}$ gas sampling syringe equipped with a stopcock and a needle (GL Science Ltd., Tokyo), a $50 \mathrm{ml}$ gas sampling bottle (GL Science Ltd., Tokyo) and an inlet pressure gauge (Kawano and Shimokawa, 1994).

To measure the internal ethane concentration the tissue sample was placed in the syringe after removing the piston rod. Immediately afterwards, the piston rod was inserted into the cylinder and pushed to reach to $20 \mathrm{ml}$ mark, the stopcock was closed and left for one hour to let ethane diffuse out of the tissue. For further extraction of ethane the piston rod was pulled back to $40 \mathrm{ml}$ mark and was held 


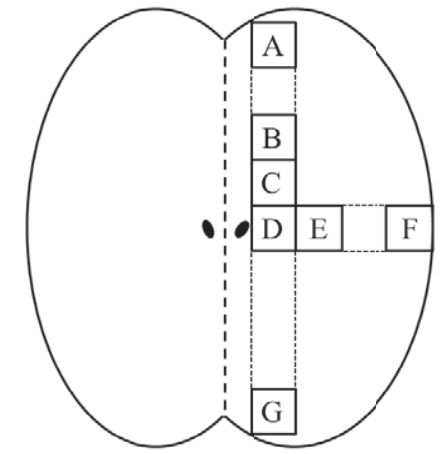

Fig. 2 Points of measuring internal gas concentration.

there for $15 \mathrm{~s}$. The negative pressure in the syringe forces ethane out of the tissue. Then $20 \mathrm{ml}$ of air was added to the syringe by opening the stopcock and immediately closing it. The needle was attached to the stopcock to make it possible to inject the air sample into the gas sampling bottle with $80 \mathrm{~mm} \mathrm{Hg}$ vacuum. Then the pressure inside the bottle was restored to atmospheric pressure by opening the cock of the gas sampling bottle and closing it immediately after the atmospheric pressure was reached. The samples for gas chromatography were collected from this gas mixture.

Few modifications were applied to the model, changing efflux model to permeation. The values of $c_{\text {ext, }, 0}, c_{\text {ext,eq }}$ and $\mathrm{c}_{0}$ were changed accordingly, as well as the equations below since $c_{\text {avg }, 0}=0$ during permeation. The new form of material balance is given in Eq. (15).

$$
\mathrm{V}_{\text {ext }} \mathrm{c}_{\text {ext }}+\mathrm{Vc}_{\mathrm{avg}}=\mathrm{V}_{\text {ext }} \mathrm{c}_{\mathrm{ext}, 0}
$$

and with rearranging it the equation defining $c_{\mathrm{ext}}$ in COMSOL Multiphysics $4.2 \mathrm{a}$ can be obtained:

$$
c_{\text {ext }}=c_{\text {ext, }, 0}-\frac{\mathrm{V}}{\mathrm{V}_{\text {ext }}} c_{\text {avg }}
$$

\section{RESULTS AND DISCUSSION}

\section{Basic properties of Japanese pear cultivars}

Weight, volume, bulk density and porosity of each sample of Japanese pear were measured according to methods explained before and all are shown in Table 1. Oushuu has the biggest fruit size with the lowest porosity, followed by Niitaka with the highest porosity. The difference in internal space volume can be a property of the cultivar but it can also be a function of the growing season and the number and size of the cells (Schotsmans et al., 2002). The fruits of Kosui are significantly smaller than Niitaka and Oushuu.
For the purpose of obtaining the accuracy of the volume measurements, the volume of a spherical object $(\mathrm{r}=$ $4.95 \pm 0.21 \mathrm{~cm}$ ) was obtained from the scanner and found to be $522.52 \mathrm{~cm}^{3}$ with $3.1 \%$ error. The accuracy of the volume measurements with NextEngline 3D laser scanner was also validated in previous studies (Raz-Bahat et al., 2009; Uyar and Erdoğdu, 2009).

Gas transfer and skin resistance to ethane

Figure $3 \mathrm{a}, \mathrm{b}$ and $\mathrm{c}$ show the changes in external concentration of ethane measured from efflux jar in comparison with the model estimations. Root mean square error values of all experiments were calculated using Eq. (17) for $c_{\text {ext }}$ values obtained from the efflux experiments $\left(c_{\text {ext, }}^{\text {obs }}\right)$ and estimated from the model ( $\left.\mathrm{c}_{\mathrm{ext}, \mathrm{i}}^{\mathrm{cal}}\right)$ and found to be in the range of $6.94 \times 10^{-9}$ to $1.11 \times 10^{-8} \mathrm{~mol}^{-1}$ for Kosui, $1.31 \times 10^{-8}$ to $1.72 \times 10^{-8} \mathrm{~mol}^{-1}$ for Niitaka and $1.24 \times 10^{-8}$ to 2.06 $\times 10^{-8} \mathrm{~mol} \mathrm{l}^{-1}$ for Oushuu, which are much smaller compared to the concentrations of ethane in orders of $10^{-7}$ mol $1^{-1}$.

$$
\mathrm{RMSE}=\sqrt{\frac{\sum_{\mathrm{i}=1}^{\mathrm{n}}\left(\mathrm{c}_{\mathrm{ext}, \mathrm{i}}^{\mathrm{obs}}-\mathrm{c}_{\mathrm{ext}, \mathrm{i}}^{\mathrm{cal}}\right)^{2}}{\mathrm{n}}}
$$

Table 2 shows $\mathrm{D}$, gas diffusivity, $\left(\mathrm{m}^{2} \mathrm{~s}^{-1}\right), \mathrm{h}_{\mathrm{c}}$, mass transfer coefficient, $\left(\mathrm{m} \mathrm{s}^{-1}\right)$ and $r_{\text {skin }}$, skin resistance, $\left(\mathrm{s} \mathrm{m}^{-1}\right)$ obtained from the models. The highest gas diffusivity occurs in Kosui, followed by Oushuu. As expected, Niitaka has the highest skin resistance to gas exchange due to noticeably lower number of lenticels on its skin which are the main sources of gas exchange. The obtained values have the same magnitude as in previous studies. However, in lack of such results for cultivars of Japanese pear, the comparison was made with apple and pear cultivars reported by Schotsmans et al. (2002). The reported skin resistance to diffusion of ethane are $6.3 \times 10^{5} \mathrm{~s} \mathrm{~m}^{-1}$ for Gala apples and $11 \times 10^{5} \mathrm{~s} \mathrm{~m}^{-1}$ for Golden delicious apples (Banks, 1985), $16 \times 10^{5} \mathrm{~s} \mathrm{~m}^{-1}$ for McIntosh apples (Solomos, 1987), $8 \times$ $10^{5} \mathrm{~s} \mathrm{~m}^{-1}$ and $4.1 \times 10^{5} \mathrm{~s} \mathrm{~m}^{-1}$ for Golden delicious (Knee, 1991), $21 \times 10^{5} \mathrm{~s} \mathrm{~m}^{-1}$ for Braeburn apples and $6.8 \times 10^{5}$ $\mathrm{s} \mathrm{m}^{-1}$ for Barlett pears (Elgar et al., 1999). For neon the values are $6.7 \times 10^{5} \mathrm{~s} \mathrm{~m}^{-1}$ for Elstar apples and $7.8 \times 10^{5}$ $\mathrm{s} \mathrm{m}^{-1}$ for Cox's Orange Pippin apples (Peppelenbos, 1996) and for oxygen $16 \times 10^{5} \mathrm{~s} \mathrm{~m}^{-1}$ for Packhams' Triumph pears and $12 \times 10^{5} \mathrm{~s} \mathrm{~m}^{-1}$ for Doyenne du Comice pears (Amarante et al., 2001). The average values obtained from the present study are $4.69 \times 10^{5} \mathrm{~s} \mathrm{~m}^{-1}$ for Kosui, $6.90 \times 10^{5}$ $\mathrm{s} \mathrm{m}^{-1}$ for Niitaka and $4.04 \times 10^{5} \mathrm{~s} \mathrm{~m}^{-1}$ for Oushuu, which are lower than Packhams' Triumph and Doyenne du Comice pears but comparable to Barlett pears and the apple cultivars.

A similar comparison was made for gas diffusivity reported by Schotsmans et al. (2004) for flesh diffusivity of $\mathrm{O}_{2}$ and $\mathrm{CO}_{2}$ in different cultivars of apple. These values are

Table 1 Basic characteristics of experimented cultivars measured at $5^{\circ} \mathrm{C}$ together with the values of standard deviation from three observations.

\begin{tabular}{clccc}
\hline Sample & Weight $(\mathrm{g})$ & Volume $\left(\mathrm{cm}^{3}\right)$ & Solid density $\left(\mathrm{g} / \mathrm{cm}^{3}\right)$ & Porosity $(-)$ \\
\hline Kosui & $267.7 \pm 6.6$ & $270.8 \pm 8.4$ & $1.038 \pm 0.001$ & $0.031 \pm 0.002$ \\
Niitaka & $578.0 \pm 18.8$ & $604.0 \pm 19.8$ & $1.051 \pm 0.005$ & $0.089 \pm 0.010$ \\
Oushuu & $716.0 \pm 72.3$ & $695.3 \pm 74.6$ & $1.039 \pm 0.007$ & $0.020 \pm 0.011$ \\
\hline
\end{tabular}




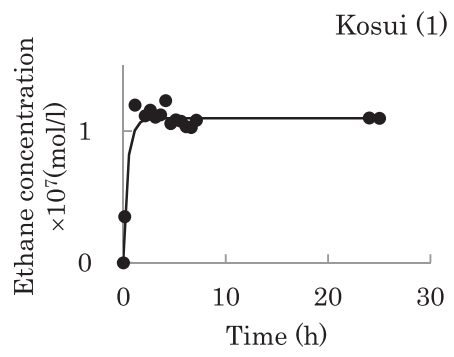

Kosui (2)

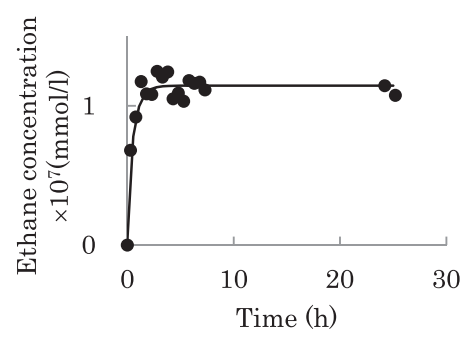

Kosui (3)

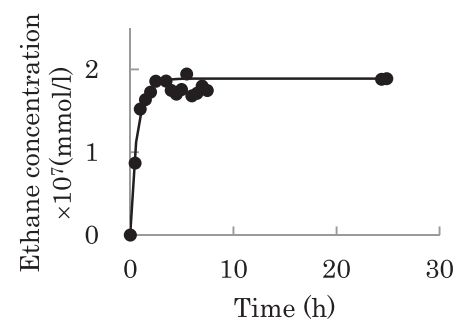

a

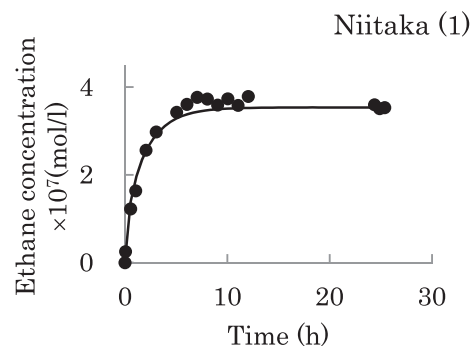

Niitaka (2)

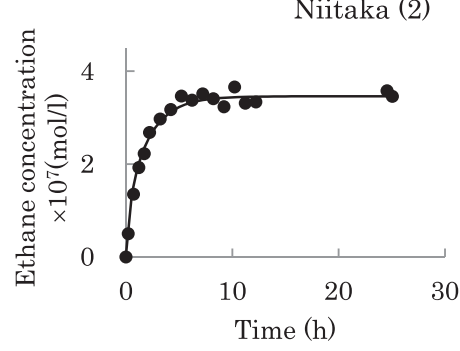

Niitaka (3)

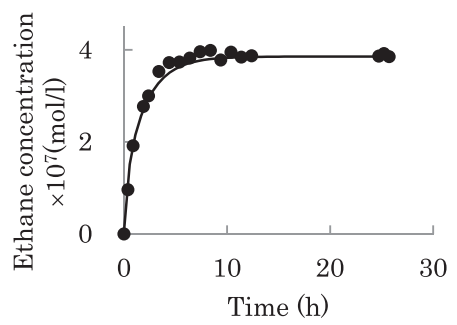

b

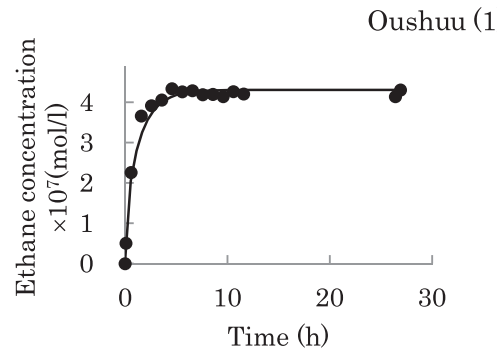

Oushuu (2)

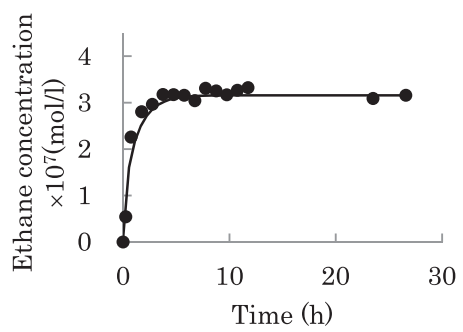

Oushuu (3)

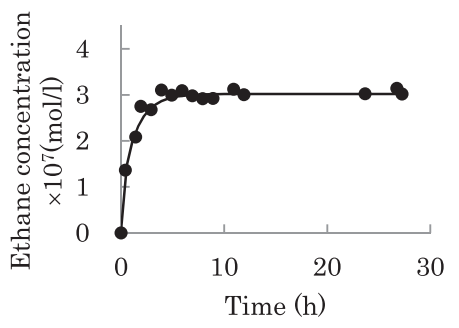

c

Fig. 3 a: External concentration of ethane in efflux jar at $5^{\circ} \mathrm{C}$ for Kosui. b: External concentration of ethane in efflux jar at $5^{\circ} \mathrm{C}$ for Niitaka. c: External concentration of ethane in efflux jar at $5^{\circ} \mathrm{C}$ for Oushuu.

Table 2 Gas transfer parameters for ethane at $5^{\circ} \mathrm{C}$ together with the values of standard deviation from three observations.

\begin{tabular}{cccc}
\hline Sample & $\mathrm{D}\left(\times 10^{-8} \mathrm{~m}^{2} / \mathrm{s}\right)$ & $\mathrm{h}_{\mathrm{c}}\left(\times 10^{-6} \mathrm{~m} / \mathrm{s}\right)$ & $\mathrm{r}_{\text {skin }}\left(\times 10^{5} \mathrm{~s} / \mathrm{m}\right)$ \\
\hline Kosui & $8.10 \pm 1.20$ & $2.17 \pm 0.39$ & $4.69 \pm 0.77$ \\
Niitaka & $3.67 \pm 0.11$ & $1.45 \pm 0.05$ & $6.90 \pm 0.24$ \\
Oushuu & $5.97 \pm 0.42$ & $2.48 \pm 0.13$ & $4.05 \pm 0.22$ \\
\hline
\end{tabular}

between $0.2 \times 10^{-8} \mathrm{~m}^{2} \mathrm{~s}^{-1}$ and $21.2 \times 10^{-8} \mathrm{~m}^{2} \mathrm{~s}^{-1}$ (Solomos, 1987; Rajapakse et al., 1989; Mannapperuma et al., 1991; Zhang and Bunn, 2000). The diffusivity of ethane in Jonica apples was reported to be in the range of $1.76 \times 10^{-8} \mathrm{~m}^{2} \mathrm{~s}^{-1}$ to $121 \times 10^{-8} \mathrm{~m}^{2} \mathrm{~s}^{-1}$ (Pham et al., 2009). The values found in the present research are well within these limits.

Skin resistance and gas diffusivity in fruits have been determined by different authors using various methods and for many cultivars, resulting in just as many values owing to the difference in the experimental methods, cultivars and measurement seasons (Schotsmans et al., 2002; Schotsmans et al., 2004). Therefore the emphasis must be put on the order of magnitude of the resulting values for skin resistance as well as gas diffusivity (Schotsmans et al., 2004). The differences in gas diffusivity of the cultivars can be attributed to a difference in intercellular volume and cell size which can be a property of the cultivar (Schotsmans et al., 2002; Schotsmans et al., 2004). Further microscopic assessment is required to confirm these differences for Kosui, Niitaka and Oushuu. The lowest effective diffusivity and the highest skin resistance belong to Niitaka with the highest porosity. One might expect higher porosity should lead to easier transport of gases inside the fruit; however it seems the case of Niitaka mostly consists of ineffective or closed porosity that would not be active in gas diffusion. The efficiency of the intercellular space as a means of aerating the tissue depends not only on the total intercellular space but also on its continuity, the degree to which it is filled with gas or liquid and the levels of $\mathrm{O}_{2}$ demand and $\mathrm{CO}_{2}$ output with which it must deal. Tissue with a small intercellular space volume can be well aerated, while tissue with a considerable intercellular space volume can be largely anaerobic, depending upon the continuity of the intercellular system (Schotsmans et al., 2004).

Determination of gas transfer properties for $\mathrm{CO}_{2}$ and $\mathrm{O}_{2}$

From co-diffusion model, Eq. (12), we could generalize gas diffusivity and skin resistance of ethane to $\mathrm{O}_{2}$ and $\mathrm{CO}_{2}$. In this equation the first term in the brackets represents pore-phase diffusion and the second term represents cell-phase diffusion. To calculate gas diffusivity for $\mathrm{O}_{2}$ and $\mathrm{CO}_{2}$ we must first estimate the values of $\mathrm{k}_{\mathrm{H}}, \mathrm{D}_{\text {air }}$ and $\mathrm{D}_{\text {cells }}$ for $\mathrm{O}_{2}$ and $\mathrm{CO}_{2}$.

In order to calculate Henry's law constant we need to 
know the concentration of $\mathrm{O}_{2}$ and $\mathrm{CO}_{2}$ in gas-phase and in dense-phase (water). Ideal gas law can be used to obtain the concentration of $\mathrm{CO}_{2}$ and $\mathrm{O}_{2}$ in gas phase, while the concentrations of these gases in water were obtained from literature and are shown in Table 3 (Tokyo Astronomical Observatory, 1987).

Applying exponential regressions to these known data allows us to obtain the relationship between Henry's law constant and temperature as in Eq. (18) for $\mathrm{O}_{2}\left(\mathrm{R}^{2}=0.98\right)$ and Eq. (19) for $\mathrm{CO}_{2}\left(\mathrm{R}^{2}=0.99\right)$.

$$
\begin{aligned}
& \mathrm{k}_{\mathrm{H}\left(\mathrm{O}_{2}\right)}=0.0478 \mathrm{e}^{-0.015 \mathrm{~T}} \\
& \mathrm{k}_{\mathrm{H}_{\left(\mathrm{CO}_{2}\right)}}=1.6671 \mathrm{e}^{-0.026 \mathrm{~T}}
\end{aligned}
$$

$\mathrm{D}_{\text {air }}$ is related to temperature according to Eq. (20).

$$
\mathrm{D}_{\text {air }}=\mathrm{D}_{0}\left(\frac{\mathrm{T}}{\mathrm{T}_{0}}\right)^{\mathrm{m}} \frac{\mathrm{P}_{0}}{\mathrm{P}}
$$

where $D_{\text {air }}\left(\mathrm{m}^{2} \mathrm{~s}^{-1}\right)$ is diffusivity of gas in air at $\mathrm{T}(\mathrm{K})$ and $\mathrm{P}(\mathrm{Pa}), \mathrm{D}_{0}$ is gas diffusivity $\left(\mathrm{m}^{2} \mathrm{~s}^{-1}\right)$ at $273.15 \mathrm{~K}$ and standard atmospheric pressure $(\mathrm{Pa})$ and $\mathrm{m}$ is the equation parameter (-). The values of $\mathrm{D}_{0}$ and $\mathrm{m}$ for ethane, $\mathrm{O}_{2}$ and $\mathrm{CO}_{2}$ are shown in Table 4 (Kagaku Kougaku Kyoukai, 1958; Elliott and Watts, 1972; Pham et al., 2009).

Since the biggest part of a cell is made of water, the values of diffusivity in water can be used for $\mathrm{D}_{\text {cells }}$ in Eq. (21) (Kagaku Kougaku Kyoukai, 1958).

Table 3 Volume of gas in 1 liter of water at atmospheric pressure (Tokyo Astronomical Observatory, 1987).

\begin{tabular}{ccc}
\hline Temperature $\left({ }^{\circ} \mathrm{C}\right)$ & $\mathrm{O}_{2}(\mathrm{~L})$ & $\mathrm{CO}_{2}(\mathrm{~L})$ \\
\hline 0 & 0.049 & 1.17 \\
20 & 0.031 & 0.88 \\
40 & 0.023 & 0.53 \\
\hline
\end{tabular}

Table 4 Parameters of Eq. (20) for ethane (Elliott and Watts, 1972), $\mathrm{O}_{2}$ and $\mathrm{CO}_{2}$ (Kagaku Kougaku Kyoukai, 1958).

\begin{tabular}{lcc}
\hline Gas & $\mathrm{D}_{0}\left(\times 10^{-5} \mathrm{~m}^{2} / \mathrm{s}\right)$ & $\mathrm{m}(-)$ \\
\hline Ethane & 1.22 & 2.00 \\
$\mathrm{O}_{2}$ & 1.78 & 1.75 \\
$\mathrm{CO}_{2}$ & 1.38 & 2.00 \\
\hline
\end{tabular}

Table 5 Gas diffusivity in water and the parameter of Eq. (21) for ethane, $\mathrm{O}_{2}$ and $\mathrm{CO}_{2}$ (Kagaku Kougaku Kyoukai, 1958).

\begin{tabular}{lccc}
\hline \multicolumn{1}{c}{ Gas } & $\begin{array}{c}\text { Temperature } \\
\left({ }^{\circ} \mathrm{C}\right)\end{array}$ & $\begin{array}{c}\mathrm{D}_{\text {water }} \\
\left(\times 10^{-9} \mathrm{~m}^{2} / \mathrm{s}\right)\end{array}$ & $\mathrm{F}\left(\mathrm{K} / \mathrm{m}^{2} \mathrm{~Pa}\right)$ \\
\hline Ethane & 25 & 1.20 & 2.79 \\
$\mathrm{O}_{2}$ & 25 & 2.60 & 1.28 \\
$\mathrm{CO}_{2}$ & 18 & 1.71 & 1.61 \\
\hline
\end{tabular}

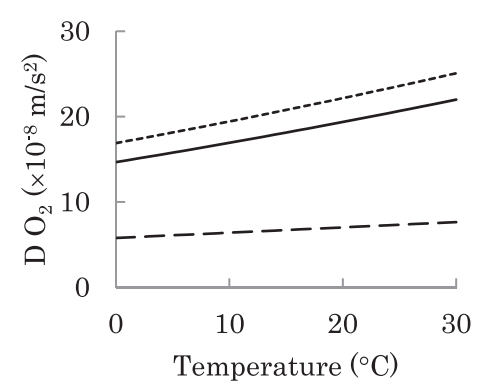

$$
\mathrm{D}_{\text {cell }} \approx \mathrm{D}_{\text {water }}=\frac{\mathrm{T}}{\mathrm{F} \mu}
$$

where $D_{\text {cell }}$ is diffusivity of gas in cells $\left(\mathrm{m}^{2} \mathrm{~s}^{-1}\right), \mathrm{D}_{\text {water }}$ is diffusivity of gas in water $\left(\mathrm{m}^{2} \mathrm{~s}^{-1}\right), \mathrm{F}$ is the equation parameter $\left(\mathrm{K} \mathrm{m}^{-2} \mathrm{~Pa}^{-1}\right)$ and $\mu$ is the viscosity of water $(\mathrm{Pa} \mathrm{s})$. Viscosity of water at $0,5,10,15,20,25$ and $30^{\circ} \mathrm{C}$ are $1.792,1.520,1.307,1.138,1.002,0.890$ and $0.797 \mathrm{mPa} \mathrm{s}$, respectively (Tokyo Astronomical Observatory, 1987). Using the data showing in Table 5 (Kagaku Kougaku Kyoukai, 1958) and the values of viscosity of water at different temperatures linear regressions were obtained to predict $\mathrm{D}_{\text {cell }}$ for $\mathrm{O}_{2}\left(\mathrm{R}^{2}=0.99\right)$ and $\mathrm{CO}_{2}\left(\mathrm{R}^{2}=0.99\right)$ at different temperatures.

Figure 4 shows the gas diffusivity estimated for $\mathrm{O}_{2}$ and $\mathrm{CO}_{2}$ at different temperatures from the data obtained for ethane at $5^{\circ} \mathrm{C}$ for Kosui, Niitaka and Oushuu. The diffusivity of $\mathrm{CO}_{2}$ is much lower than $\mathrm{O}_{2}$ despite the fact its solubility in water is higher than $\mathrm{O}_{2}$. There are two paths for gas transport in fruit flesh: through cells and from the pores. The diffusivity of gases in the cells $\left(D_{\text {water }}\right)$ is so small compared to that in the pores $\left(D_{\text {air }}\right)$ that diffusion in the cells takes place mainly on a local level, from a pore into its surrounding cells, rather than on the macro-scale (Pham et al., 2009). Figure 5 shows the skin resistance estimated for $\mathrm{O}_{2}$ and $\mathrm{CO}_{2}$ at different temperatures from the data obtained for ethane at $5^{\circ} \mathrm{C}$ for Kosui, Niitaka and Oushuu. Skin resistance is not influenced by harvest date but is dependent on free space volume which is depending on the cultivar, the growing season and the number and the size of the cells (Elgar et al., 1999; Schotsmans et al., 2002). As expected the diffusivity of oxygen and carbon dioxide are the highest in Kosui, followed by Oushuu and Niitaka and the skin resistance of these two gases are the highest for Niitaka, similar to our findings for ethane gas.

Model validation

Seven tissue samples were cut from three pear fruits. Ethane was extracted and injected into gas chromatograph. From the models estimations, seven points of the geometry equivalent to the tissue sample locations were picked to solve their ethane concentration values. It is difficult to estimate the extraction efficiency since it is impossible to extract all ethane from the tissue (Kawano and Shimokawa, 1994), hence, to compare the result of the validating experiments with the model output, relative values were calculated by setting one standard point. Another reason for using relative values is the concentration of gas is from a 1 $\mathrm{cm}^{3}$ cube of fruit flesh while the data from the model be-

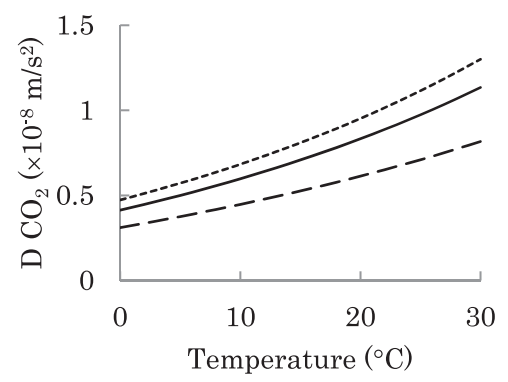

Fig. 4 Changes of gas diffusivity for $\mathrm{O}_{2}$ and $\mathrm{CO}_{2}$ in three examined cultivars: (Kosui -.-----, Niitaka ----, Oushuu $\longrightarrow$ ) 

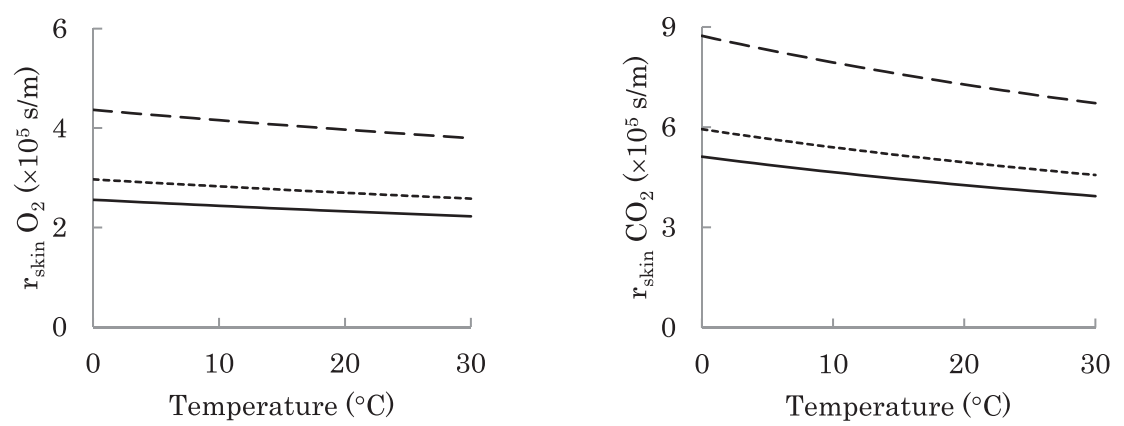

Fig. 5 Changes of skin resistance for $\mathrm{O}_{2}$ and $\mathrm{CO}_{2}$ in three examined cultivars: (Kosui ---..-., Niitaka ---- , Oushuu - )

Table 6 Relative values (-) of internal gas concentration obtained from the model and the experiments for Oushuu.

\begin{tabular}{llcc}
\hline Experiments & & & Model average \\
\hline \multirow{3}{*}{ Set 1} & $\mathrm{D}$ & 1.00 & $1.00 \pm 0.00$ \\
& $\mathrm{~F}$ & 2.98 & $2.95 \pm 0.11$ \\
Set 2 & $\mathrm{G}$ & 1.53 & $1.57 \pm 0.13$ \\
& $\mathrm{~A}$ & 1.00 & $1.00 \pm 0.00$ \\
Set 3 & $\mathrm{~B}$ & 0.36 & $0.47 \pm 0.01$ \\
& $\mathrm{C}$ & 1.00 & $1.00 \pm 0.00$ \\
\hline
\end{tabular}

longs to one point. The relative value is the concentration of ethane in one point divided to that of the standard point, hence it is dimensionless. The standard point can be any of the measurement points.

The locations of the cubes from top, side and bottom of the fruit were recorded for all samples. In Extract node of COMSOL Multiphysics software, it is possible to set a grid or a specific point to calculate its concentration at a specific time. The time was set equal to the length of the experiment and the point on the geometry was set to represent the center of each cube in the experiment.

The relative values are shown in Table 6. Set 1, 2 and 3 refers to the number of times the experiments were repeated on three different pears; hence there are different standard points for each set, shown with relative value of equal to 1. A comparison between relative values obtained from the model with those of the experiments shows in most cases these values are very close. The differences in other cases might be due to shape and size differences between different fruits of each cultivar as well as experimental errors. The validation experiments were conducted only on Oushuu because the methodology of the experiments and the modeling system in all steps were the same for all three cultivars; therefore it is considered enough to validate our methodology.

\section{CONCLUSION}

The present study was conducted in order to obtain some of the physical and gas transfer properties of three cultivars of Japanese pear due to lack of such information for Kosui, Niitaka and Oushuu. Also for a better understanding and more accurate results the actual 3D geometry of the fruit was obtained with a 3D laser scanner and was imported in COMSOL Multiphysics 4.2a to perform the mathematical modeling. Gas diffusivity and skin resistance to gas diffusion found to be dependent on the cultivar. Gas diffusivity for ethane was found to be $8.10 \pm 1.2,3.67 \pm$ 0.11 and $5.97 \pm 0.42\left(\times 10^{-8} \mathrm{~m}^{2} \mathrm{~s}^{-1}\right)$ for Kosui, Niitaka and Oushuu, respectively. Intercellular space volume and cell size can cause the differences in diffusivity between cultivars. Niitaka has the highest skin resistance due to a noticeably lower number of lenticels on the skin. Results of the generalizing gas transfer properties to $\mathrm{O}_{2}$ and $\mathrm{CO}_{2}$, the most important gases in storage, showed the gas diffusivity increases with increasing of temperature while skin resistance decreases. Diffusivity of $\mathrm{CO}_{2}$ is much lower than $\mathrm{O}_{2}$ basically due to the different path of diffusion. For the purpose of validating the model, experiments were conducted to measure the internal ethane concentration and compare these data with a representative point in the model, which showed satisfactory results.

\section{REFERENCES}

Amarante, C., Banks, N. H., Ganesh, S. 2001. Relationship between character of skin cover of coated pears and permeance to water vapour and gases. Postharvest Biol. Technol. 21: 291-301.

Banks, N. H. 1985. Estimating skin resistance to gas diffusion in apples and potatoes. J. Exp. Bot. 36: 1842-1850.

Borsa, J., Chu, R., Sun, J., Linton, N., Hunter, C. 2002. Use of $\mathrm{CT}$ scans and treatment planning software for validation of the dose component of food irradiation protocols. Radiat. Phys. Chem. 63: 271-275.

Celik, H. K., Rennie, A. E. W., Akinci, I. 2011. Deformation behaviour simulation of an apple under drop case by finite element method. J. Food Eng. 104: 293-298.

E. Rezagah, M., Ishida, S., Tanaka, F., Hamanaka, D., Uchino, T. 2013. Three-dimensional heat transfer modeling of Japanese pear (Pyrus pyrifolia) during tempering. Food Sci. Technol. Res. 19: 765-772.

Elgar, H. J., Lallu, N., Watkins, C. B. 1999. Harvest date and crop load effects on a carbon sioxide-related storage injury of 'Braeburn' apple. HortScience 34: 305-309.

Elliott, R. W., Watts, H. 1972. Diffusion of some hydrocarbons in air: a regularity in the diffusion coefficients of a homologous series. Can. J. Chem. 50: 31-34.

Fabbri, A., Cevoli, C., Alessandrini, L., Romani, S. 2011. Numerical modeling of heat and mass transfer during coffee roasting process. J. Food Eng. 105: 264-269.

Goñi, S. M., Purlis, E., Salvadori, V. O. 2007. Threedimensional reconstruction of irregular foodstuffs. J. Food Eng. 82: 536-547. 


\section{EBRAHIM REZAGAH ET AL.}

Ho, Q., Verlinden, B. E., Verboven, P., Vandewalle, S., Nicolaï, B. M. 2006. A permeation-diffusion-reaction model of gas transport in cellular tissue of plant materials. J. Exp. Bot. 57: 4215-4224.

Kagaku Kougaku Kyoukai (Ed.) 1958. Kagaku Kougaku Binran. 2nd edn., Maruzen Co., Ltd., Tokyo, pp 1184.

Kawano, T., Shimokawa, K. 1994. A simple method for vacuum extraction and quantitative determination of internal ethylene of excised apple tissue. J. Jpn. Soc. Hort. Sci. 63: 453459.

Kelkar, S., Stella, S., Boushey, C., Okos, M. 2011. Developing novel 3D measurement techniques and prediction method for food density determination. Procedia Food Science, 1: 483491.

Knee, M. 1991. Rapid measurement of diffusion of gas through the skin of apple fruits. HortScience 26: 885-887.

Mannapperuma, J. D., Singh, R. P., Montero, M. E. 1991. Simultaneous gas diffusion and chemical reaction in foods stored in modified atmospheres. J. Food Eng. 14: 167-183.

Nieto, A., Salvatori, D., Castro, M., Alzamora, S. 2004. Structural changes in apple tissue during glucose and sucrose osmotic dehydration: shrinkage, porosity, density and microscopic features. J. Food Eng. 61: 269-278.

Peppelenbos, H. 1996. The use of gas exchange characteristics to optimize CA storage and MA packaging of fruits and vegetables. PhD Dissertation, University of Wageningen, The Netherlands, pp 157.

Pham, Q. T., Bulens, I., Ho, Q., Verlinden, B. E., Verboven, P., Nicolaï, B. 2009. Simultaneous measurement of ethane diffusivity and skin resistance of 'Jonica'apples by efflux experiment. J. Food Eng. 95: 471-478.

Pham, Q. T., Schotsmans, W., Ho, Q., Verlinden, B. E., Verboven, P., Nicolaï, B. M. 2008. Simultaneous measurement of neon diffusivity and skin resistance of 'Braeburn' and 'Jonica' apples. Postharvest Biol. Technol. 50: 53-63.

Rajapakse, N. C., Hewett, E. W., Banks, N. H., Cleland, D. J., Austin, P. C. 1989. Oxygen diffusion in apple fruit flesh. In Proc Fifth Int Controlled Atmosphere Research Conf.

Raz-Bahat, M., Faibish, H., Mass, T., Rinkevich, B. 2009. Three-dimensional laser scanning as an effective tool for coral surface area measurements. Limnol. Oceanogr. Methods 7: 657-663.

Schotsmans, W., Verlinden, B. E., Lammertyn, J., Nicolaï, B. M. 2004. The relationship between gas transport properties and the histology of apple. J. Sci. Food Agric. 84: 1131-1140.

Schotsmans, W., Verlinden, B. E., Lammertyn, J., Peirs, A., Jancsók, P. T., Scheerlinck, N., Nicolaï, B. M. 2002. Factors affecting skin resistance measurements in pipfruit. Postharvest Biol. Technol. 25: 169-179.

Solomos, T. 1987. Principles of gas exchange in bulky plant tissues. HortScience 22: 766-771.

Tokyo Astronomical Observatory (Ed.) 1987. Riku nenpyo. Maruzen, Co., Ltd., Tokyo, pp 1007.

Uyar, R., Erdoğdu, F. 2009. Potential use of 3-dimensional scanners for food process modeling. J. Food Eng. 93: 337343.

Zhang, J., Bunn, J. M. 2000. Oxygen diffusivities of apple flesh and skin. Trans. ASABE 43: 359-363. 